\title{
ASPECTOS MORFOLÓGICOS, GERMINAÇÃO E DESENVOLVIMENTO INICIAL DE PLÂNTULAS DE Archontophoenix alexandrae (F. Mueller) H. Wendl. e Drude (ARECACEAE) EM DIFERENTES SUBSTRATOS ${ }^{1}$
}

\author{
Hamilton César de Oliveira Charlo², Fabíola Vitti Môro ${ }^{3}$, Vanessa Lorencini da Silva², Breno Marques da \\ Silva e Silva ${ }^{3}$, Silvano Bianco ${ }^{5}$ e José Roberto Môro ${ }^{3}$
}

\begin{abstract}
RESUMO - Este trabalho teve por objetivo descrever a morfologia dos diásporos e as suas fases de germinação, bem como determinar o substrato mais adequado para a germinação das sementes e o crescimento das plântulas de palmeira-da-rainha (Archontophoenix alexandrae (F. Mueller) H. Wendl. e Drude). Periodicamente, unidades representativas de cada fase de germinação foram retiradas para as descrições morfológicas. Os substratos utilizados foram Plantmax ${ }^{\circledR}$, areia, terra (latossolo roxo) e outro com proporções iguais de terra, areia e esterco (TAE). Foi instalado um experimento em delineamento inteiramente casualizado. Avaliaram-se a porcentagem, o tempo médio de germinação e o crescimento inicial das plântulas aos 135 dias após a emergência, com base na altura, diâmetro do colo e número, comprimento e largura das folhas. As sementes são albuminosas, com endosperma ruminado e oleaginoso, e o embrião é lateral, periférico e relativamente indiferenciado. A germinação é do tipo criptocotiledonar hipógea, iniciando-se com a formação de uma massa de células indiferenciadas na depressão micropilar. Essa massa de células torna-se cilíndrica, com a diferenciação dos primórdios caulinares e radiculares. Concomitantemente, ocorre o desenvolvimento de raízes adventícias no eixo embrionário. $\mathrm{O}$ substrato mais indicado para a germinação de sementes de palmeira-da-rainha é o Plantmax ${ }^{\circledR}$, porém, para o crescimento inicial, indica-se Plantmax ${ }^{\circledR}$ e TAE.
\end{abstract}

Palavras-chaves: Palmeira-da-rainha, diásporo, morfologia e nutriente.

\section{MORPHOLOGICAL ASPECTS, GERMINATION AND INITIAL SEEDLING DEVELOPMENT OF Archontophoenix alexandrae (F. Mueller) H. Wendl. e Drude (ARECACEAE) IN DIFFERENT SUBSTRATES}

\begin{abstract}
This work aimed at describing the morphology and germination phases of diaspores, in order to determine a more suitable substrate for germination and growth of Queen Palm seedlings. Representative units of each germination phase were removed periodically for the morphological descriptions. The used substrates were Plantmax ${ }^{\circledR}$, sand, rich soil and a substrate with equal ratios of soil, sand and manure (TAE). The experiment was performed in a completely randomized design. The percentage and the time of germination and the initial growth of seedlings at 135 days after the emergency were evaluated on the basis of seedling height, crown diameter, leaf number, length and width of leaves. Seeds are albuminous, with a ruminated and oleaginous endosperm. The embryo is lateral, peripheral and relatively undifferentiated. The germination is hypogeal cryptocotyledonary, initiating with the formation of an undifferentiated cell mass in the micropilary depression. This mass of cells becomes cylindrical, with the differentiation of the shoot and root primordium. It is concluded that for the germination of Queen Palm seeds, the most indicated substrate is Plantmax®, however for the initial growth, both Plantmax ${ }^{\circledR}$ and TAE are indicated.
\end{abstract}

Keyword: Queen Palm, diaspore, morphology and nutrient.

\footnotetext{
${ }^{1}$ Recebido em 22.05.2006 e aceito para publicação em 02.10.2006.

${ }^{2}$ Graduação em Agronomia da Universidade Estadual Paulista (UNESP)/Faculdade de Ciências Agrárias e Veterinárias - Campus Jaboticabal (FCAV)/Departamento de Biologia Aplicada a Agropecuária (DBAA). E-mail: <hamiltoncharlo@ yahoo.com.br>. ${ }^{3}$ UNESP/FCAV/DBAA. Via de Acesso Prof. Dr. Paulo Donato Castellane, s/n. Jaboticabal-SP. E-mail: <fabiola@ fcav.unesp.br>. ${ }^{4}$ Programa de Pós-Graduação em Agronomia da UNESP/FCAV. E-mail: <silvabms@ fcav.unesp.br>.
} 


\section{INTRODUÇÃO}

O interesse pelo cultivo de palmeiras ornamentais tem aumentado significativamente devido ao seu indiscutível valor paisagístico, proporcionando beleza e serenidade à paisagem de campos abertos, ruas, jardins, parques e praças (STRINGHETA et al., 2004; LORENZI et al., 2005).

As espécies do gênero Archontophoenix são largamente cultivadas como ornamentais nos trópicos e subtrópicos de ambos os hemisférios (PINHEIRO, 1986; LORENZI et al., 2005). Archontophoenix alexandrae (F. Muller) H.Wendl. e Drude, conhecida popularmente por seafórtia ou palmeira real australiana, é uma espécie originária de Queensland, na Austrália, região tropical com altitude inferior a $1.100 \mathrm{~m}$, sendo utilizada no Brasil e em outros países em parques e jardins (MAEDA et al., 1987; LORENZI et al., 2005). É uma palmeira comum em sua área de distribuição, sendo encontrada em agrupamentos, frequientemente ao longo das margens de rios. As plantas dessa espécie formam um sistema radicular muito denso, o que a torna muito importante para prevenir a erosão em margens de rios (STRINGHETA et al., 2004).

A palmeira real australiana começou a ser cultivada para produção de palmito, sobretudo na região litorânea de Santa Catarina. A partir de matéria produzida na EPAGRI (Itajaí, SC) e divulgada pelo Globo Rural em 2001, tal atividade vem-se expandindo rapidamente pela Região Centro-Sul do país (CHAIMSOHN e DURIGAN, 2002). Segundo Maeda et al. (1987), a propagação de seafórtia é feita exclusivamente por sementes. Atraídos pela cor vermelha, os pássaros ingerem os frutos inteiros, regurgitando-os despolpados, atuando, assim, como dispersores da espécie (VALLILO et al., 2004).

O estudo do potencial germinativo de palmeiras representa um avanço significativo para a domesticação e a exploração racional de seu potencial econômico, alimentar e energético (CUNHA e JARDIM, 1995). Pinheiro e Araújo-Neto (1987) defenderam o fato de que estudos descritivos da germinação de sementes de palmeiras são importantes para o melhor conhecimento do processo germinativo e básico para o desenvolvimento técnico eficiente da produção de mudas. A germinação de sementes de palmeiras é geralmente caracterizada por dificuldades, as quais variam desde as características morfológicas das sementes até as peculiaridades fisiológicas do processo germinativo (CUNHA e JARDIM, 1995).
A composição mineral ou teor dos nutrientes nos tecidos foliares depende de diversos fatores, como: planta (espécie, variedade, tipo de folha, idade etc.), solo, fertilizante, clima, práticas culturais, pragas e doenças (MALAVOLTA et al., 1997). De modo geral, a absorção de nutrientes, na maioria das culturas, segue o padrão da curva de crescimento (acúmulo de matéria seca). O conhecimento da quantidade de nutrientes acumulada na planta, em cada estádio de desenvolvimento, fornece informações importantes que podem auxiliar o programa de adubação das culturas. No entanto, as curvas de absorção de nutrientes refletem o que a planta necessita e não o que deve ser aplicado, uma vez que é preciso considerar a eficiência de aproveitamento dos nutrientes, que é variável, segundo as condições climáticas, o tipo de solo, o sistema de irrigação, e o manejo cultural entre outros fatores. De modo mais efetivo, essas curvas auxiliam o programa de adubação, principalmente na quantidade dos nutrientes que devem ser aplicados nos distintos estádios fisiológicos da cultura (VILLASBÔAS, 2001).

Para aproveitar o potencial econômico das palmeiras regionais e incorporá-las à lista de produtos comerciais, torna-se necessária a ampliação dos estudos básicos e aplicados para um melhor conhecimento de sua diversidade, ocupação no ecossistema, evolução, adaptação e desenvolvimento de métodos adequados para o manejo e utilização de seu potencial (MIRANDA et al., 2001). Dessa forma, o objetivo do presente trabalho foi descrever morfologicamente a semente, o desenvolvimento pós-seminal e da plântula, além de determinar o substrato mais adequado para a germinação e crescimento inicial de plântulas de Archontophoenix alexandrae.

\section{MATERIAL E MÉTODOS}

As matrizes de Archontophoenix alexandrae pertencem à Coleção de Palmeiras do Viveiro Experimental da FCAV/UNESP-Jaboticabal-SP. Posteriormente à coleta dos frutos de cinco plantas-matriz, a descrição e análise dos diásporos foram realizadas no Laboratório de Morfologia Vegetal do Departamento de Biologia Aplicada à Agropecuária - FCAV-UNESP, Jaboticabal, SP. A cidade de Jaboticabal possui temperatura média anual de $22,2^{\circ} \mathrm{C}$, sendo a temperatura máxima média anual de $28,9^{\circ} \mathrm{C}$ e a temperatura mínima média anual de $16,8^{\circ} \mathrm{C}$ (UNESP, 2005). 
O processo de beneficiamento dos frutos compreendeu a retirada manual do pericarpo, por meio de sua fricção contra uma peneira de malha de aço, como descrito por Stringheta et al. (2004). Posteriormente, o teor de água do lote de sementes foi determinado, após a secagem de quatro repetições de 10 sementes em estufa a $105 \pm 3{ }^{\circ} \mathrm{C}$, durante $24 \mathrm{~h}$, conforme o recomendado pelas Regras de Análise de Sementes - RAS (BRASIL, 1992).

Para os estudos morfológicos, os diásporos foram cortados nos sentidos longitudinal e transversal, sendo observados em estereomicroscópio com câmara clara. Para a descrição do processo germinativo, uma amostra de 50 diásporos foi colocada para germinar em bandejas plásticas contendo Sphagnum sp. A intervalos representativos dos diversos estádios da germinação, foram coletadas amostras das plântulas, em fases seqüenciais de desenvolvimento, evidenciando: surgimento do botão germinativo; desenvolvimento da raiz primária e surgimento de raízes adventícias; expansão da primeira e segunda bainhas; início do crescimento da primeira folha; e expansão da folha primária. Para as descrições morfológicas, foram usadas as terminologias empregadas por Tomlinson (1960; 1961; 1990).

Para avaliar o efeito dos substratos na germinação e desenvolvimento inicial da plântula, foram utilizados sacos plásticos de 1 litro contendo areia, terra (latossolo roxo), Plantmax $®$ ou uma mistura com proporções iguais de terra, areia e esterco (TAE), onde as sementes foram colocadas para germinar em profundidade de semeadura de $1 \mathrm{~cm}$. Posteriormente, os sacos foram mantidos sob sombrite $50 \%$ e regados diariamente com água. $\mathrm{O}$ delineamento experimental foi inteiramente casualizado, sendo utilizadas quatro repetições de 25 sementes por substrato.

A germinação foi avaliada semanalmente, de acordo com a formação da plântula normal, critério recomendado pelas Regras de Análise de Sementes (BRASIL, 1992). Posteriormente, foram calculados as porcentagens e os tempos médios de germinação, conforme Labouriau e Agudo (1987). Aos 135 dias após a semeadura, foram realizadas mensurações de comprimento, diâmetro do colo, número de folhas e altura das plântulas, segundo o método descrito por Clement e Bovi (2000).

As partes aéreas e raízes das plântulas foram separadas e, posteriormente, lavadas e colocadas para secar em estufa de renovação forçada de ar a 60 - 70 ${ }^{\circ} \mathrm{C}$, por $96 \mathrm{~h}$, quando se determinou a biomassa seca. Após a secagem, o material vegetal foi moído e submetido à digestão por via úmida, de acordo com o método proposto por Sarruge e Haag (1974) e a subseqüente determinação dos teores dos macronutrientes $(\mathrm{N}, \mathrm{P}$, $\mathrm{K}, \mathrm{Ca}, \mathrm{Mg}$ e $\mathrm{S})$. O nitrogênio total $\left(\mathrm{N}_{\text {total }}\right)$ e o fósforo (P) foram determinados pelos métodos semimicrokjedahl e colorimétrico do ácido fosfovanadato-molíbdico, respectivamente, conforme descrito por Sarruge e Haag (1974). Para a determinação do potássio (K), do cálcio (Ca) e do magnésio ( $\mathrm{Mg}$ ) foi utilizado o método descrito por Jorgensen (1977), através da espectrofotometria de absorção atômica. O teor de (S) foi determinado pelo método turbidimétrico, descrito por Vitti (1989). Os acúmulos totais dos nutrientes pelas plântulas foram obtidos multiplicando-se o valor da massa seca total pelo teor total de cada nutriente extraído pela plântula, aos 135 dias após a semeadura.

A porcentagem de germinação foi transformada pelo [arco-seno $(\%)^{0,5}$, porém nas tabelas são apresentadas as médias originais. As comparações entre as médias foram feitas com a aplicação do teste de Tukey a 5\% de probabilidade (PIMENTELGOMES, 1987).

\section{RESULTADOS E DISCUSSÃO}

As sementes de seafortia têm forma arredondada e endosperma ruminado e de consistência dura (Figura 1A). Semelhantemente, Viana (2003) descreveu o diásporo de Livistona rotundifolia (Lam.) Mart. como globoso e com a maior parte ocupada pelo endosperma rígido. Segundo Vallilo et al. (2004), o teor de substâncias voláteis representa $47,72 \%$ da composição total da semente de seafórtia, indicando alto teor de água e alto valor calórico das sementes, o que está associado à presença de lipídios e carboidratos. Segundo Vallilo et al. (2004), a grande quantidade de fibras presentes em sementes de seafórtia é provavelmente a causa da sua dureza.

O embrião de seafórtia é lateral, periférico e relativamente indiferenciado, com aproximadamente $4 \mathrm{~mm}$ de comprimento, de forma cônica, com uma das extremidades côncava, no interior da qual se encontra uma pequena protuberância. A outra extremidade é arredondada e mais afilada (Figura 1B). De forma semelhante, Aguiar e Mendonça (2003) descreveram

R. Árvore, Viçosa-MG, v.30, n.6, p.933-940, 2006 
o embrião de Euterpe precatoria Mart. como indiviso e cônico, distinguindo uma região distal, mais estreita e com muitos feixes vasculares, e uma região proximal, mais alargada, de coloração mais escura, apresentando, em vista frontal, uma minúscula elevação central por onde emergirá a raiz primária.

De acordo com o conceito de Tomlinson (1961), a germinação de sementes de seafórtia é criptocotiledonar hipógea, sendo que o desenvolvimento se inicia a partir de uma massa de células indiferenciadas na depressão micropilar (Figura 1C). Posteriormente, essa massa de células torna-se cilíndrica, com a diferenciação dos primórdios caulinares e radiculares (Figura 1D), sendo o primeiro envolto por uma bainha fechada (Figura 1E). Concomitantemente, ocorre o desenvolvimento de raízes adventícias no eixo embrionário (Figura 1E,
F). O sistema radicular é fasciculado, com raízes adventícias diferenciadas e várias raízes laterais, com poucos pelos absorventes (Figura 1G). De acordo com Tomlinson (1990), as palmeiras raramente apresentam uma camada pilífera considerável.

O primórdio caulinar é constituído por três bainhas que envolvem a primeira folha jovem, as quais se abrem, sucessivamente, permitindo a emergência da folha primária. A primeira bainha é localizada próximo ao eixo embrionário e apresenta menor extensão que as demais. A folha primária é bífida, com nervuras paralelas típicas (Figura 1E). De acordo com o conceito de Tomlinson (1960; 1961), observou-se que a germinação de seafórtia é do tipo adjacente ligulada, pois o cotilédone não apresenta grande alongamento, ocorrendo o desenvolvimento da plântula, adjacente à semente (Figura $1 \mathrm{G})$.
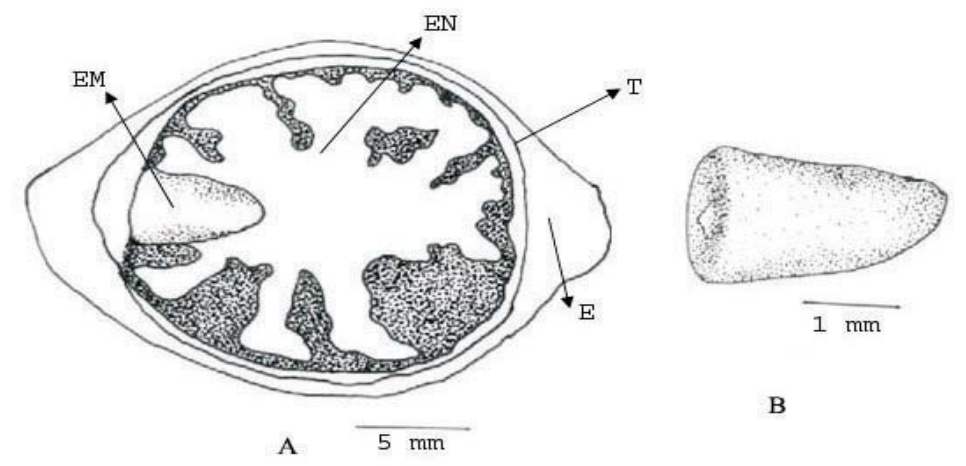

B

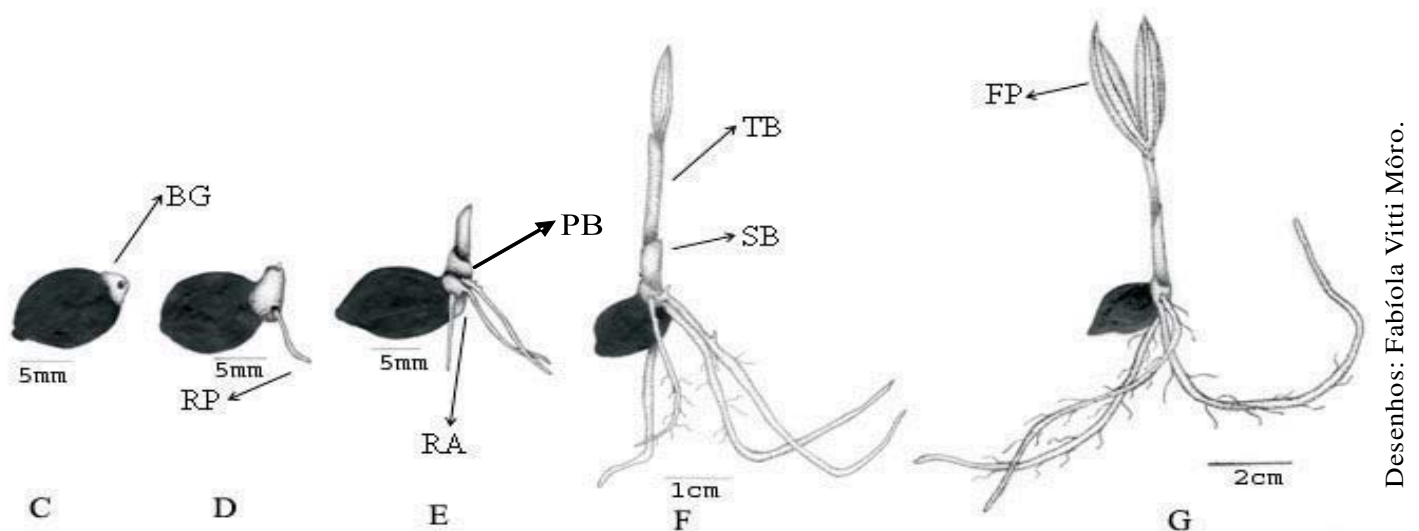

Figura 1 - A: Corte longitudinal do diásporo, embrião e fases da germinação de sementes de Archontophoenix alexandrae. $\mathrm{EM}=$ embrião; $\mathrm{EN}=$ endosperma $; \mathrm{E}+\mathrm{T}=$ endocarpo+tegumento; $\mathrm{BG}=$ botão germinativo; $\mathrm{RP}=\mathrm{raiz}$ primária; $\mathrm{PB}=$ primeira bainha; $\mathrm{SB}=$ segunda bainha; $\mathrm{RA}=$ raiz adventícia; $\mathrm{FP}=$ folha primária.

Figure 1 -Longitudinal section of the diaspore, embryo and germination phases of Archontophoenix alexandrae. EM= embryo; $E N=$ endosperm $; E+T=$ endocarp + tegument $; B G=$ germinative button $; R P=$ primary root $; P B=$ first sheath; $S B=$ second sheath; $R A=$ adventitious root $F P=$ first leaf.

R. Árvore, Viçosa-MG, v.30, n.6, p.933-940, 2006 
O teor de água de $36,8 \pm 1,6 \%$ para as sementes de seafórtia do lote estudado está dentro dos níveis ótimos para essa espécie (CASTELLANI et al., 2001). As sementes recalcitrantes têm sua viabilidade reduzida quando o teor de água atinge valores inferiores àqueles considerados críticos; quando iguais ou inferiores àqueles considerados letais, há perda total de viabilidade, sendo essa sensibilidade à dessecação dependente da espécie (MARTINS et al., 1999).

Em geral, houve germinação e crescimento inicial de sefórtia em todos os substratos testados, mas a maior porcentagem de germinação foi observada com Plantmax ${ }^{\circledR}$ (Tabela 1). Dessa forma, esse substrato proporcionou condições mais adequadas para a germinação de sementes dessa espécie, fato esse que, provavelmente, está relacionado com a umidade e aeração desse substrato, promovendo maior desenvolvimento das raízes e, consequientemente, maior capacidade de emergência das plântulas. No entanto, segundo Maeda et al. (1987) as sementes de seafórtia germinaram igualmente em areia, terra, vermiculita grossa, vermiculita fina e em outras misturas de partes iguais de areia e terra, enquanto Andrade et al. (1999) assumiram que a vermiculita é o substrato mais adequado para o desenvolvimento de Euterpe edulis, em comparação com areia e solo.

Nos demais substratos avaliados, as porcentagens de germinação tiveram valores inferiores e semelhantes entre si (Tabela 1). Possivelmente, na areia a alta drenagem reduziu a disponibilidade de água necessária, enquanto na terra e na TAE a maior compactação superficial representou uma barreira mecânica de maior dificuldade de transposição para as plântulas. De acordo com Castellani et al. (2001), as sementes de seafórtia recentemente coletadas apresentam uma taxa de germinação de 67,5\% em areia, enquanto Figliolia (1988) observaram cerca de $50 \%$ de germinação em sementes da mesma espécie com 8 a $13 \%$ de teor de água e Stringheta et al. (2004), 94 e $96 \%$ de germinação para os teores de água de 24,6 e 41,2\%, respectivamente, também nessa mesma espécie.

Martins et al. (1999) verificaram que as sementes de E. espiritosantensis são recalcitrantes, apresentando porcentagem alta de germinação $(90,0 \%$ a $87,5 \%)$ em vermiculita quando o teor inicial de água foi de $51,4 \%$ a 46,6\%. Abaixo de uma faixa de teor de água situada entre 40,7 e 51,4\%, os valores de germinação e vigor foram significativamente reduzidos. A mortalidade total das sementes foi observada, com a redução no teor de água das sementes a uma faixa situada entre 13,4 e $15,8 \%$.

Os menores tempos médios de germinação foram observados no TAE e no Plantmax ${ }^{\circledR}$, conforme os resultados da Tabela 1. De acordo com Castellani et al. (2001), as sementes de palmeiras seafórtia demoram cerca de 12 a 20 dias para iniciar a protrusão da raiz primária, enquanto Lorenzi et al. (2005) afirmaram que as sementes de seafórtia levam cerca de 75 dias para germinar.

Tabela 1 - Porcentagem de germinação (G\%), tempo médio de germinação (TMG), diâmetro do colo (DC), comprimento de folha (CF), número de folhas (NF) e altura de plântulas (ALT) de Archontophoenix alexandrae, aos 135 após a semeadura em diferentes substratos

Table 1 -Germination percentage $(G \%)$, mean time to germination $(T M G)$, diameter of the crown (DC), leaf length $(C F)$, leaf number $(N F)$ and seedling height (ALT) of Archontophoenix alexandrae at 135 days after sowing in different substrates

\begin{tabular}{lcccccc}
\hline Substrato* & $(\mathrm{G} \%)$ & TMG $($ Dias $)$ & DC $(\mathrm{cm})$ & CF $(\mathrm{cm})$ & NF & ALT $(\mathrm{cm})$ \\
\hline Plantmax ${ }^{\circ}$ & $86,3 \mathrm{~A}$ & $61,8 \mathrm{BC}$ & $15,42 \mathrm{~A}$ & $8,89 \mathrm{AB}$ & $2,56 \mathrm{~A}$ \\
Terra & $72,5 \mathrm{~B}$ & $65,3 \mathrm{AB}$ & $13,33 \mathrm{~B}$ & $8,62 \mathrm{AB}$ & $2,25 \mathrm{~B}$ \\
Areia & $75,0 \mathrm{~B}$ & $70,1 \mathrm{~A}$ & $12,08 \mathrm{~B}$ & $8,10 \mathrm{~B}$ & $1,78 \mathrm{C}$ & $2,02 \mathrm{~B}$ \\
TAE* & $75,0 \mathrm{~B}$ & $53,9 \mathrm{C}$ & $15,34 \mathrm{~A}$ & $9,27 \mathrm{~A}$ & $2,48 \mathrm{~A}$ \\
\hline CV\% & 2,99 & 6,5 & 20,51 & 18,88 & $2,24 \mathrm{~B}$ \\
\hline
\end{tabular}

* Médias seguidas da mesma letra na coluna não diferem entre si, pelo teste de Tukey a nível de 5\% de probabilidade.

${ }^{*}$ Means followed by the same letter within a column are not significantly different by Tukey's test at $5 \%$ of probability. 
Os maiores incrementos em altura, aos 135 dias após a semeadura, foram observados em plântulas cultivadas em Plantmax $®$, seguido da terra e TAE, que tiveram valores semelhantes entre si (Tabela 1). Isso está, provavelmente, relacionado ao fato de o Plantmax ${ }^{\circledR}$ ter nutrientes mais prontamente disponíveis, além de apresentar melhor estruturação e retenção de umidade. O menor desenvolvimento em areia está, possivelmente, relacionado à falta de nutrientes e à baixa retenção de umidade desse substrato. Em condições favoráveis, as palmeiras de Archontophoenix apresentam crescimento rápido quando comparadas com outras palmeiras cultivadas (PINHEIRO, 1986).

Ocomprimento de folhas foi maior em TAE, comparado à areia, e com valores semelhantes na terra e no Plantmax®. O número de folhas de plântulas de seafórtia foi maior no Plantmax ${ }^{\circledR}$ e TAE do que na areia (Tabela 1).

O diâmetro do colo, comprimento e número de folhas e altura foram maiores no Plantmax ® e em TAE (Tabela 1). Esse maior desenvolvimento está, possivelmente, relacionado à maior quantidade de nutrientes disponíveis para as plântulas nos estádios iniciais de crescimento.

Os menores valores de incremento em altura, comprimento de folha, diâmetro do colo e número de folhas foram observados em areia (Tabela 1) do que em TAE, terra e Plantmax ${ }^{\circledR}$, devido às baixas concentrações de nutrientes nesse substrato. Isso indica que as plântulas de seafórtia são exigentes em nutrientes nos estádios iniciais de desenvolvimento, sendo necessário semeá-las em substratos com boa fertilidade.
De igual forma, Iossi et al. (2003) observaram que as plântulas de Phoenix roebelenii O’Brien tinham menor desenvolvimento quando se usavam os substratos areia, vermiculita e serragem.

As plântulas apresentaram maior crescimento no Plantmax ${ }^{\circledR}$ e a matéria seca, maiores teores de N, P, K, $\mathrm{Ca}, \mathrm{Mg}$ e valor intermediário para o S. Os teores de K, $\mathrm{Ca}$ e $\mathrm{Mg}$ foram semelhantes nas plantas cultivadas em substrato TAE e em Plantmax $®$. Para as plantas germinadas em TAE, os teores de $\mathrm{P}$ foram intermediários e os de $\mathrm{N}$ e $\mathrm{S}$, inferiores aos do Plantmax $®$. No substrato terra, os teores foram intermediários em todos os nutrientes estudados, exceto em $\mathrm{NeS}$, que se igualaram aos valores observados em Plantmax ${ }^{\circledR}$. As plantas cultivadas em areia tiveram o pior desempenho, com os menores teores para todos os macronutrientes, exceto o $\mathrm{P}$, que se igualou ao observado em Plantmax $®$ (Tabela 2$)$.

Os maiores acúmulos de N, P, K, Ca, Mg e S ocorreram nas plântulas em substrato Plantmax ${ }^{\circledR}$, com acúmulos semelhantes de K no substrato TAE e no Plantmax ${ }^{\circledR}$ e com valores intermediários nos demais nutrientes. Na terra, os valores de acúmulo em todos os nutrientes foram intermediários e os menores acúmulos ocorreram no substrato areia (Tabela 2). Apesar da deficiência de nutrientes na areia, Figliolia et al. (1993) afirmaram que a areia é o substrato mais adequado para a realização de testes de aferição da germinação, em que se deseja efetuar comparação com outros substratos, uma vez que, com o uso da areia, obtêmse, em geral, melhores resultados de germinação.

Tabela 2 - Acúmulos médios totais (AMTM) e teores médios totais (TMTM) de macronutrientes em plântulas de Archontophoenix alexandrae, aos 135 dias após a semeadura em diferentes substratos

Table 2 - Total accumulation averages (AMTM) and total average content of macronutrients (TMTM) in Archontophoenix alexandrae seedlings at 135 days after the sowing in different substrates

\begin{tabular}{lcccccccccccc}
\hline Tratamento & \multicolumn{4}{c}{ AMTM - g/planta } & \multicolumn{4}{c}{ TMTM - g/kg de massa de matéria seca } \\
\hline Substrato/Nutriente & $\mathrm{N}$ & $\mathrm{P}$ & $\mathrm{K}$ & $\mathrm{Ca}$ & $\mathrm{Mg}$ & $\mathrm{S}$ & $\mathrm{N}$ & $\mathrm{P}$ & $\mathrm{K}$ & $\mathrm{Ca}$ & $\mathrm{Mg}$ & $\mathrm{S}$ \\
\hline Areia & 3,66C & $0,95 \mathrm{C}$ & $2,60 \mathrm{C}$ & $1,11 \mathrm{D}$ & $0,43 \mathrm{C}$ & $0,38 \mathrm{C}$ & $15,09 \mathrm{~B}$ & $3,93 \mathrm{~A}$ & $10,72 \mathrm{C}$ & $4,60 \mathrm{C}$ & $1,79 \mathrm{C}$ & $1,56 \mathrm{C}$ \\
Plantmax® & $14,71 \mathrm{~A}$ & $2,45 \mathrm{~A}$ & $16,54 \mathrm{~A}$ & $4,06 \mathrm{~A}$ & $3,27 \mathrm{~A}$ & $1,43 \mathrm{~A}$ & $21,42 \mathrm{~A}$ & $3,55 \mathrm{~A}$ & $23,9 \mathrm{AB}$ & $5,90 \mathrm{AB}$ & $4,75 \mathrm{~A}$ & $2,08 \mathrm{~B}$ \\
Terra & $6,72 \mathrm{~B}$ & $0,54 \mathrm{D}$ & $7,62 \mathrm{~B}$ & $1,83 \mathrm{C}$ & $0,91 \mathrm{C}$ & $0,87 \mathrm{~B}$ & $19,60 \mathrm{~A}$ & $1,58 \mathrm{C}$ & $22,26 \mathrm{~B}$ & $5,37 \mathrm{~B}$ & $2,67 \mathrm{~B}$ & $2,54 \mathrm{~A}$ \\
TAE & $5,46 \mathrm{~B}$ & $1,45 \mathrm{~B}$ & $16,48 \mathrm{~A}$ & $3,27 \mathrm{~B}$ & $2,56 \mathrm{~B}$ & $0,49 \mathrm{C}$ & $10,27 \mathrm{C}$ & $2,74 \mathrm{~B}$ & $30,98 \mathrm{~A}$ & $6,22 \mathrm{~A}$ & $4,83 \mathrm{~A}$ & $0,92 \mathrm{D}$ \\
\hline $\mathrm{CV}(\%)$ & 8,86 & 13,10 & 20,88 & 8,21 & 13,89 & 8,88 & 7,32 & 9,99 & 15,27 & 5,24 & 8,53 & 7,05 \\
\hline
\end{tabular}

* Médias seguidas da mesma letra na coluna não diferem entre si, pelo teste de Tukey a 5\% de probabilidade.

"Means followed by the same letter within a column are not significantly different by Tukey's test at $5 \%$ of probability.

R. Árvore, Viçosa-MG, v.30, n.6, p.933-940, 2006 


\section{CONCLUSÃO}

Os estudos morfológicos envolvendo a unidade de dispersão, a germinação e o crescimento inicial de Archontophoenix alexandrae podem auxiliar o conhecimento do ciclo biológico, da regeneração natural e do manejo e conservação dessa espécie.

O Plantmax $®$ foi o substrato mais adequado para a germinação de sementes de seafórtia, mas o crescimento inicial dessas plântulas foi satisfatório, tanto no substrato Plantmax ${ }^{\circledR}$ quanto no TAE.

\section{REFERÊNCIAS BIBLIOGRÁFICAS}

AGUIAR, M.O.; MENDONÇA, M.S. Morfoanatomia de semente de Euterpe precatoria Mart.(Palmae). Revista Brasileira de Sementes, v. 25, n. 1, p. 37-42, 2003.

ANDRADE, A.C.S. et al. Reavaliação de efeito de substrato e da temperatura na germinação de sementes de palmiteiro (Euterpe edulis Mart.).

Revista Árvore, v. 23, n. 3, p. 279-83, 1999.

BRASIL. Ministério da Agricultura e Reforma Agrária. Regras para análise de sementes. Brasília : LAVARV/SNAD, 1992. 365 p.

CASTELLANI, E.D.; SILVA, A.; DEMATTÊ, M.E.S.P. Conservação de sementes de palmeira seafórtia. Revista Brasileira de Horticultura Ornamental, v. 7, n. 2, p. 135-141, 2001.

CHAIMSOHN, F.P.; DURIGAN, M.E. Rentabilidade do cultivo de palmeira-real versus. pupunha para produção de palmito. In: ENCONTRO PARANAENSE SOBRE PALMITOS CULTIVADOS: O agronegócio pupunhae palmeira-real, 1., 2004, Pontal do Paraná. Anais... Pontal do Paraná: 2004. v. 105. p. 131-136

CLEMENT, C.R.; BOVI, M.L.A. Padronização de medidas de crescimento e produção em experimento com pupunheiras para palmito. Acta Amazonica, v. 30, n. 3, p. 349-362, 2000.

CUNHA, A.C.C.; JARDIM, M.A.G. Avaliação do potencial germinativo em açaí (Euterpe oleracea Mart.) variedades preto, branco e espada. Boletim do Museu Paraense Emílio Goeldi Série Botânica, v. 11, n. 1, p. 55-60, 1995.
UNIVERSIDADE ESTADUAL DE SÃO PAULO DEPARTAMENTO DE CIÊNCIAS EXATASESTAÇÃO AGROCLIMATOLÓGICA - UNESP, 2005. (http://www.fcav.unesp.br/departamentos/ cienciasexatas/caract/estacao/resenha71_00.htm).

FIGLIOLIA, M.B. Conservação de sementes de essências florestais. Boletim Técnico do Instituto Florestal, v. 42, n. 1, p. 1-18, 1988.

FIGLIOLIA, M.B.; OLIVEIRA, E.C.; PINÃRODRIGUES, C.F.M. Análise de sementes. In: AGUIAR, I.B.; PIÑA-RODRIGUES, F.C.M.; FIGLIOLIA, M.B. (Eds.). Sementes florestais tropicais. São Paulo: ABRATES, 1993. p. 275-302.

IOSSI, E. et al. Efeitos de substratos e temperaturas na germinação de sementes de Tamareira-Anã (Phoenix roebelenii O’Brien). Revista Brasileira de Sementes, v. 25, n. 2, p. 63-69, 2003.

JORGENSEN, S. S. Metodologia utilizada para análises químicas de rotina: guia analítico. Piracicaba: CENA, 1977. 24 p.

LABOURIAU, L. G.; AGUDO, M. On the physiology of seed germination in Salvia hispanica L. I. Temperature effects. Anais da Academia Brasileira de Ciências, v. 59, p. 57-69, 1987.

LORENZI, H. et al. Palmeira no Brasil: exóticas e nativas. 2. ed. Nova Odessa: Plantarum, $2005.303 \mathrm{p}$.

MAEDA, J.A. et al. Germinação de sementes da palmeira Archontophoenix alexandrae. In: ENCONTRO NACIONAL SOBRE

ARBORIZAÇÃO URBANA, 2., 1987, Maringá. Anais... Maringá: Sociedade Brasileira de Arborização Urbana, 1987. p. 99-107.

MALAVOLTA, E.; VITTI, G.C.; OLIVEIRA, S.A. Avaliação do estado nutricional das plantas: princípios e aplicações. Piracicaba: POTAFOS, 1997. 201 p.

MARTINS, C.C.; NAKAGAWA, J.; BOVI, M.L.A. Tolerância à dessecação de sementes de palmito-vermelho (Euterpe espiritosantensis Fernandes). Revista Brasileira de Botânica, v. 22, n. 3, p. 391-396, 1999. 
MIRANDA, I.P.A. et al. Frutos de Palmeiras da Amazônia. Manaus: MCTINPA, 2001. 120 p.

PIMENTEL-GOMES, F. Curso de estatística experimental. São Paulo: Nobel, 1987. 467 p.

PINHEIRO, C.U.B. Germinação de sementes de palmeiras: Revisão bibliográfica. Teresina: EMBRAPA - UEPAE de Teresina, 1986. 102 p.

PINHEIRO, C.U.B.; ARAÚJO-NETO, A. Descrição do processo germinativo de semente de babaçu (Orbignya phalerata Mart.). São Luis: EMAPA, 1987. 7 p. (Comunicado Técnico, 14).

SARRUGe, J. R.; HAAG, H. P. Análises químicas em plantas. Piracicaba: ESALQ/ USP, $1974.56 \mathrm{p}$.

STRINGHETA, A.C.O. et al. Secagem e armazenamento de sementes de palmeira real australiana (Archontophoenix alexandrae).

Revista Brasileira de Armazenamento, v. 29, n. 1, p. 51-57, 2004.

TOMLINSON, P.B. Essays on the morphology of palms; germination and seedlings. Principes, v. 4 , n. 2 , p. $56-61,1960$.
TOMLINSON, P.B. Anatomy of the monocotyledons. In: TOMLISON, P.B. II PALMAE. Oxford: C.R. Metcalf, 1961.p. 308-311.

TOMLINSON, P.B. The structural biology of palms. Oxford: Clarendon Press, 1990. 460 p.

VIANA, F.A.P. Estudos sobre germinação e morfo-anatomia de diásporos e da plântula de Livistona rotundifolia (Lam.) Mart. (Arecaceae). 2003. 76 f. Dissertação (Mestrado em Agronomia) - Universidade Estadual de São Paulo, Jaboticabal, 2003.

VALLILO, M.I. et al. Composição química das sementes de Archontophoenix alexandrae $\mathrm{H}$. Wendl. e Drude (ARECACEAE). Revista Árvore, v. 28, n. 5, p. 676-679, 2004.

VILLAS-BÔAS, R.L. Doses de nitrogênio para pimentão aplicadas de forma convencional e através da fertirrigação. 2001. 123 f. Tese (Livre Docência) - Universidade Estadual de São Paulo, Botucatu, 2001.

VITTi, G. C. Avaliação e interpretação do enxofre no solo e na planta. Jaboticabal: FUNEP, 1989. 37p. 